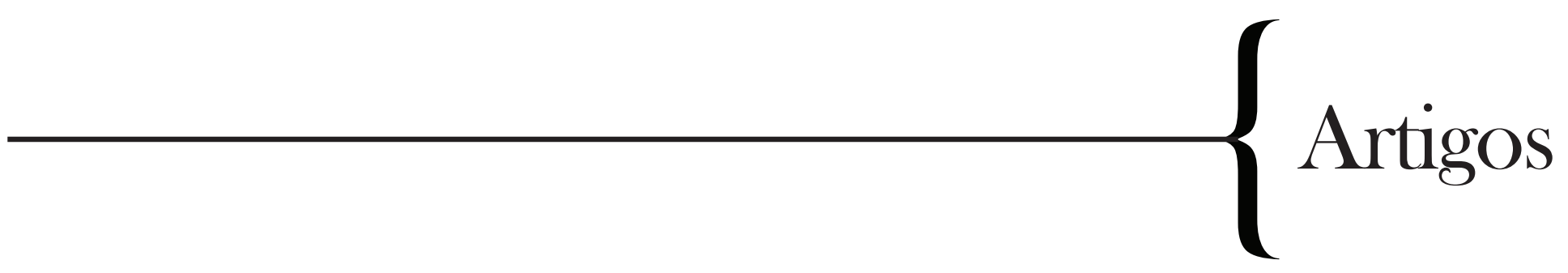




\section{Fenomenologia hermenêutica das ciências naturais: os desafios do Science Studies}

\section{Hermeneutical phenomenology of natural sciences: the challenges of the Science Studies}

Prof. Dr. Antonio Augusto Passos Videira

Este artigo, composto de duas partes, descreve, no seu primeiro módulo, das tentativas recentes de aproximação da hermenêutica com as análises epistemológicas sobre as ciências naturais, de modo a superar o velho obstáculo de que aquela corrente filosófica não se interessaria ou, o que seria pior, nada poderia dizer sobre disciplinas como física, química, entre outras. A segunda parte é dedicada à descrição de algumas ideias avançadas pelo filósofo búlgaro Dimitri Ginev em favor de uma concepção hermenêutica das ciências naturais.

PALAVRAS-ChAVE Hermenêutica; Science studies; Ginev; Galison.

This article, divided in two parts, describes, first, some recent attemps to employ hermeneutics to the analysis of the natural sciences from the perspective of epistemology in order to overcome the old prejudice, which states that hermeneutics doesn't concern disciplines like physics or chemistry. The second part is dedicated to the description of the attempts elaborated by the Bulgarian philosopher Dimitri Ginev to unite the hermeneutical tradition with natural sciences.

KEY-WORDS Hermeneutics; Science Studies; Ginev; Galison

*Este trabalho contou com o apoio financeiro do CNPq e do Programa Prociência (FAPERJ/UERJ). Ao longo dos anos, muito aprendi em discussões com Róbson Ramos dos Reis, Fernando Fragozo e André Luís de Oliveira Mendonça. Aos três amigos, o meu muito obrigado. 


\section{Introdução}

Este artigo é composto de duas partes, relativamente autônomas entre si. Em parte, tal autonomia explica-se pelo fato de que elas foram escritas em momentos diferentes. A primeira parte foi apresentada em 2007 no II Congresso Luso-brasileiro de Fenomenologia em Lisboa; já a apresentação da segunda parte ocorreu em 2011 na cidade de Évora, no IV Congresso Luso-brasileiro de Fenomenologia. A despeito de algumas diferenças entre elas, não penso que me engano que ambas contituem uma certa totalidade coerente, ainda mais se não for esquecido o seu propósito maior, a saber: divulgar a existência de uma corrente filosófica que procura aproximar a hermenêutica das ciências naturais.

O objetivo deste artigo consiste em analisar a proposta de Dimitri Ginev em direção a uma fenomenologia hermenêutica da prática científica contemporânea. Em particular, será necessário investigar se o "uso" que o filósofo búlgaro faz das ideias defendidas pelos Science Studies - em particular, aquelas elaboradas por P. Galison - são suficientes para contribuir para a construção de uma imagem de ciência, que coloca em primeiro plano a produção de diferenças (em todo e qualquer nível), sem que a compreensão dessa dinâmica produtora de diferenças tenha que necessariamente ser explicada através da incorporação de uma perspectiva política. A intenção explícita de evitar - a todo custo? - a incorporação da dimensão política como elemento com força explicativa da produção de diferenças leva Ginev a desconsiderar o papel que a contingência desempenha, não apenas em Galison, mas em grande parte dos Science Studies. Essa desconsideração é digna de nota, uma vez que a sua estratégia está, grosso modo, fundada numa menção explícita a elementos constitutivos da estratégia dos Science Studies, bem como - e talvez principalmente - na incorporação de resultados obtidos por esta perspectiva. Mas, seria possível ficar com os resultados sem a estratégia? Em nosso entender, a proposta de Ginev é insatisfatória.

\section{$-1-$}

O objetivo deste artigo concentra-se em tecer algumas considerações acerca da questão: seria possível elaborar uma filosofia hermenêutica das ciências naturais? Não alimento nenhuma pretensão em defender uma resposta definitiva para esse problema. O meu propósito consiste em chamar a atenção para um movimento (HEELAN, 1998 ; HEELAN; SCHULKIN, 1998) que, até onde me é possível perceber, tem recebido pouco destaque no cenário da filosofia 
da ciência atual. A principal razão que explica o porquê do desinteresse pela possível relação da hermenêutica com a filosofia das ciências naturais deve-se ao fato de que a primeira não organizaria a filosofia da ciência, a qual encontra-se dispersa e com disputas internas. $\mathrm{O}$ último debate que movimentou, como um todo, o ambiente da filosofia da ciência concernia o realismo científico. Inúmeros trabalhos foram publicados sem que se chegasse a uma solução para o problema de como explicar o progresso científico.

Ao mesmo tempo em que os filósofos da ciência enredavam-se em discussões sobre o realismo científico, a história e a sociologia da ciência, bem como uma junção desses dois domínios - os Science Studies, ganhavam adeptos (VIDEIRA, 2005). A década de 1970 foi fecunda em resultados, obtidos pela história e pela sociologia da ciência, que minaram a crença nos modelos epistemológicos produzidos pelas principais correntes filosóficas então conhecidas: o Positivismo Lógico e o Racionalismo Crítico. Mesmo a Nova Filosofia da Ciência teve que rever alguns de seus pressupostos. Com relação a essa última vertente, as críticas foram, contudo, menos fortes, uma vez que ela seria uma das responsáveis pelo abandono do Positivismo Lógico e do Racionalismo Crítico, ao mesmo tempo em que contribuiu para o surgimento dos Science Studies (BOMBASARO, 1992).

As críticas ao Positivismo Lógico e ao Racionalismo Crítico criaram um vazio no interior da filosofia da ciência, sendo crescentes as suas dificuldades para conduzir as discussões filosóficas sobre a ciência. Nos últimos 15 anos, aproximadamente, ganhou força um movimento cujo objetivo principal parece ser o de mostrar a viabilidade de se constituir uma ponte entre a hermenêutica e a ciência natural. Para alguns dos adeptos dos Science Studies, como Don Ihde e Joseph Rouse (ROUSE, 1990), a hermenêutica forneceria os elementos necessários para a constituição do universo conceitual unificador dos resultados da história e da sociologia da ciência, dando um novo vigor às reflexões sobre a ciência. Esse movimento favorável a uma hermenêutica das ciências naturais é constituído por grupos variados que defendem concepções diversas do que é a ciência e do que cabe à filosofia da ciência. Ainda assim, é possível perceber, ao menos no que se refere à rejeição de certas características atribuídas à ciência, alguma unidade entre eles.

Até meados da década de 1960, predominou no mundo filosófico anglo-saxão uma concepção filosófica de ciência organizada a partir de critérios e métodos lógico-empíricos. A perspectiva dominante nas análises sobre a natureza da ciência, em especial, da ciência natural, era analítica. No século XX, o principal representante dessa perspectiva foi o Positivismo Lógico. A partir 
da década seguinte (1970), ocorreu a sua substituição por outra concepção, que defendia uma vinculação com modelos históricos.

Pode-se pensar o século passado como a época que mostrou a impossibilidade da filosofia da ciência em determinar a natureza do conhecimento científico. Tal impossibilidade decorreria do fato de que racionalidade e historicidade teriam sido entendidas como categorias (aqui, em sentido latu) pertencentes a tradições filosóficas distintas e excludentes. A divisão da filosofia entre analítica e continental (ou histórica) contribuiu para a manutenção desse ponto de vista. Segundo a perspectiva analítica, o nível normativo é metodológico, enquanto que a história é descritiva, não podendo, assim, determinar normas.

Os principais pressupostos da perspectiva analítica são os seguintes: a) realismo; b) linguagem científica universal; c) teorias da verdade, em particular aquela determinada pela correspondência com a natureza. A síntese da imagem analítica de ciência seria: "existe um mundo externo, o qual, em princípio, pode ser exaustivamente descrito em linguagem científica". O cientista, como observador e usuário da linguagem, captura os fatos externos do mundo em proposições que são verdadeiras se elas correspondem aos fatos, e falsas se não correspondem. A ciência é, idealmente, um sistema linguístico, no qual as proposições verdadeiras estão numa relação um-a-um com os fatos, incluindo-se aqueles que não são diretamente observados e os que ocorreram em tempos muitos distantes. Os eventos ocultos são descritos por teorias, inferidas da observação. $\mathrm{O}$ mecanismo explanatório oculto do mundo pode ser descoberto a partir daquilo que é facultado à observação. O ser humano, enquanto cientista, é percebido como estando à parte do mundo e como capaz de experimentar e teorizar sobre ele de modo objetivo desinteressado. Ou seja, o cientista adota, obrigatoriamente, para que as suas observações possam ter valor cognitivo, uma atitude neutra com relação ao mundo.

As principais características do Círculo de Viena, talvez a mais expressiva corrente vinculada a essa perspectiva analítica, são: a) aplicação de conceitos lógicos para a reconstrução racional dos conceitos científicos; b) exigência de verificabilidade dos enunciados; c) procura de critérios de significado empírico e a consequente recusa da metafísica; d) superação da distinção entre ciências naturais e ciências humanas através do recurso à tradução geral para a linguagem da ciência unificada. As principais teses defendidas por Popper são: a) existência de uma lógica da investigação; b) critério de demarcação; c) objetividade científica; d) recusa da lógica indutiva. Para o filósofo austríaco, somente a lógica dedutiva possibilita uma avaliação segura sobre a validade das propo- 
sições científicas. O critério de demarcação é fundamental para distinguir as teorias científicas das pseudocientíficas: caberia à experiência falsear as teorias, determinado assim o seu caráter de cientificidade.Para o Círculo de Viena, o critério de demarcação é o de verificabilidade. Finalmente, no tocante à objetividade científica, Popper aceita a ideia, comum entre os adeptos do Positivismo Lógico, segundo a qual a objetividade do conhecimento científico depende de uma base empírica, que consiste em proposições existenciais singulares.

Apesar de ser difícil mostrar a presença de um movimento de convergência conceitual, é possível preencher as perspectivas analíticas, caso pensemos que cada teoria posterior considera-se a si própria como uma aproximação da anterior, ainda que essa interpretação seja feita em seus próprios termos. Este é o chamado princípio de correspondência. Tal aspecto do desenvolvimento da ciência permite-nos pensar que, apesar da tese da subdeterminação, a ciência natural é progressiva instrumentalmente, na medida em que se dispõe de várias possibilidades pragmáticas de predição e controle de eventos empíricos por meio de experimentos e da construção de teorias. O sucesso pragmático e as leis aproximadas são sempre relativas a fenômenos locais particulares. Esta última tese inviabiliza a concepção de uma verdade universalizável.

Um dos principais pontos da imagem analítica de ciência a receber críticas foi aquele referente à inferência de teorias a partir de observações, uma vez que isto não pode ser feito conclusivamente, posto que, em princípio, sempre existe um número infinito de teorias que podem se ajustar adequadamente aos fatos. Esta tese é conhecida como subdeterminação das teorias pelos dados empíricos. Outra tese que quebrou a confiança no modelo analítico foi a chamada theory-ladenness: toda assunção observacional descrevendo dados empíricos deve ser expressa em alguma linguagem contendo predicados descritivos gerais.

As consequências provocadas pela tese da subdeterminação são muitas. Uma delas afirma que nenhuma teoria real, em um estágio qualquer de desenvolvimento, pode ser considerada verdadeira empiricamente num sentido proposicional estrito. Uma consequência desta última afirmação enfraqueceu o positivismo e fortaleceu o realismo: as questões epistemológicas foram colocadas em segundo plano com relação às ontológicas. Ainda que a perspectiva analítica tenha se interessado mais tarde por questões ontológicas, ela, contudo, não prestou atenção aos seguintes eventos, que lhe eram externos:

a) Desenvolvimento de uma compreensão hermenêutica das ciências humanas na tradição continental de Dilthey e Weber até Gadamer e Habermas e na filosofia anglo-saxã graças aos seguidores do segundo Wittgenstein; 
b) Discussão sociológica da epistemologia iniciada por Marx e continuada por Durkheim e sucessores;

c) Fortalecimento de perspectivas naturalistas e historicistas tais como aquelas defendidas por Quine, por um lado, e por Kuhn e Feyerabend, de outro. Essas tendências foram consideradas por aqueles que abraçavam ideias do Positivismo Lógico como sendo relativistas.

A perspectiva continental, ou histórica, abrange ao menos três grandes vertentes:

a) A "Nova Filosofia da Ciência" - Norwood Hanson, Stephen Toulmin, Thomas Kuhn, Imre Lakatos e Paul Feyerabend;

b) A Epistemologia Francesa - Alexandre Koyré, Gaston Bachelard, Georges Canguilhem e Michel Foucault, e;

c) Escola de Frankfurt - Theodor Adorno, Max Horkheimer e Jürgen Habermas.

Talvez o único ponto a ligar todas as três seja a recusa radical em aceitar a perspectiva analítica. Mesmo entre os adeptos da chamada Nova Filosofia da Ciência, é impossível encontrar uma tendência unificadora, persistindo uma grande diversidade entre os seus adeptos.

A rejeição à tendência analítica centrou-se nos seguintes pontos:

a) Toda observação está carregada de teorias (esta tese já foi mencionada anteriormente e recebeu a denominação theory-ladenness);

b) Rejeição da tese da invariância do significado, pois a história da ciência revela a ocorrência de mudanças radicais (as revoluções científicas propostas por Kuhn);

c) Questionamento do monismo metodológico e do ideal da ciência unificada, principalmente criticado por Feyerabend e sintetizado no seu famoso princípio "tudo vale" (anything goes no original);

d) Rejeição por parte de Lakatos do critério de demarcação de Popper, uma vez que, para o primeiro, as teorias científicas mais notáveis mostram-se incapazes em evitar os mais improváveis estados observáveis de coisas;

e) Revalorização da metafísica.

A influência de Kuhn e Feyerabend se deu principalmente no recurso à história como elemento-chave para a compreensão da natureza da ciência. Eles defenderam o abandono da crença numa ciência natural como constituindo a descoberta progressiva e cumulativa de verdades reais e ingênuas sobre o mun- 
do externo. A reinterpretação da história da ciência em termos de sequências de revoluções conceituais tornou insustentável a historiografia indutivista.

$\mathrm{Na}$ segunda metade do século XIX, ganharam força e importância o instrumentalismo, isso no interior da perspectiva analítica, aqui entendida como uma modalidade específica de positivismo, e a hermenêutica, a qual, segundo Dilthey, deveria ser capaz de fornecer as ciências humanas o seu fundamento metodológico. A hermenêutica era então considerada como interpretação, contrastando com o empirismo, o qual tomava os dados sensoriais como diretos, literais, neutros e não interpretados. Aqui se faz presente uma distinção forte entre natureza (externa e objetiva) e sociedade humana. Ao final do século passado, essas diferenças foram sumarizadas por Habermas do seguinte modo:

a) Nas ciências naturais, a experiência é objetiva, testável (isto é, reprodutível) e independente da explicação teórica; nas ciências humanas, os dados são inseparáveis da teoria, uma vez que aquilo que é considerado dado o é à luz de interpretações teóricas;

b) Nas ciências naturais, as teorias são modelos, ou seja, construções artificiais. As explicações são obtidas através do uso do modelo hipotético-dedutivo, enquanto que nas ciências humanas, as teorias são construções miméticas dos fatos e o critério de uma boa teoria é a compreensão do sentido e das intenções;

c) Nas ciências naturais, as relações nomológicas são externas, seja com relação aos objetos, seja com relação aos observadores: elas são correlacionais. Nas ciências humanas, as relações são internas, já que os objetos estudados são constituídos pelas interrelações que eles mantêm entre si e com outros objetos, e também porque as relações são criadas pelas categorias humanas do entendimento;

d) Nas ciências naturais, a linguagem é entendida como exata, precisa e quantitativa; em suma, ela é percebida como matemática; enquanto que nas ciências humanas, a linguagem é equívoca e imprecisa;

e) Nas ciências naturais, o sentido é separado dos fatos; nas ciências humanas, os sentidos são constitutivos dos fatos, uma vez que os dados consistem de documentos, inscrições, comportamento intencional, regras, teorias e artefatos humanos, os quais são inseparáveis dos seus sentidos para os agentes.

Para a Nova Filosofia da Ciência (Hanson, Toulmin, Kuhn, Feyerabend, Lakatos, Laudan, etc.), os cinco tópicos descritos acima podem ser reescritos do seguinte modo quando aplicados à ciência natural: a) os dados não podem 
ser distinguidos da teoria, já que aquilo que conta como dado é determinado graças a alguma interpretação teórica e os fatos devem ser reconstruídos segundo tal interpretação; b) os modelos são externos, sendo o modo segundo o qual os fatos são vistos; c) as relações nomológicas são internas, uma vez que o que conta como fato é construído por aquilo que a teoria afirma sobre as interrelações mantidas pelos fatos; d) a linguagem é metafórica e inexata e só pode ser fortalecida caso sejam aceitas distorções na dinâmica histórica do desenvolvimento científico; e) os sentidos são determinados pela teoria, ou seja, eles são entendidos através de coerência teórica e não por meio de uma correspondência com fatos.

A posição favorável à elaboração de uma hermenêutica para as ciências naturais é igualmente devedora dos debates dos anos 1980 a respeito da suposta oposição entre Modernidade e Pós-Modernidade (MURPHY, 1990; ROUSE, 1991b). Esse debate, que permanece, até hoje, sem conclusão, apresentou alguns resultados, aceitos por aqueles que propugnavam a necessidade de se organizar o domínio dos Science Studies (VIDEIRA, 2005):

a) Existe um sentimento generalizado de falência da filosofia da ciência (é também comum encontrarmos referência ao fim da epistemologia), principalmente daquela que se inspirou nas vertentes positivista e popperiana, uma vez que as imagens de ciência produzidas por essas duas perspectivas filosóficas não se assemelhavam em praticamente nada às descrições apresentadas pela história e pela sociologia da ciência;

b) Esse sentimento de falência surgiu inicialmente entre aqueles que se dedicavam à Nova Filosofia da Ciência, à história da ciência (Koyré, Galison, Pestre) e à sociologia da ciência tal como praticada na Grã-Bretanha (Bloor, Barnes, Collins, Pinch e Pickering);

c) O vazio, instaurado por esse sentimento de falência, é, em parte, preenchido pela análise dos pressupostos, dos fundamentos e das consequências originadas na filosofia e propugnadas pelos adeptos mais radicais dos Science Studies. Em outras palavras, alguns filósofos da ciência de nossos dias, como Arthur Fine, Larry Laudan, Michael Friedman e Mario Bunge recusam-se a aceitar muito daquilo que se pode verificar como pertencendo ao universo conceitual dos Science Studies. Alguns dos adeptos deste último domínio defendem-se invocando a fecundidade de suas análises, as quais, segundo eles, retratam melhor aquilo que se passa nos locais, dentro dos quais a ciência é produzida (GALISON; STUMP, 1996). 
Até meados da década de 1980, a filosofia da ciência anglo-saxã era dominada por debates que opunham realistas a antirrealistas, relativistas a realistas e, ainda, indutivistas a dedutivistas. O resultado mais interessante da dificuldade em mostrar quem teria razão a respeito de como explicar o sucesso das ciências naturais sugeriu que o modelo filosófico sobre o qual se assentava a discussão era equivocado. O principal equívoco origina-se no fato de a ciência ser encarada como uma estrutura epistemológica. Desse modo, e coerente com a perspectiva que rejeita a percepção da ciência como possuindo apenas uma estrutura epistemológica, os debates a respeito do realismo esgotaram a capacidade explanatória da filosofia epistemológica da ciência, segundo a expressão de Rouse. Foi, portanto, necessário ampliar a gama de recursos conceituais empregados para analisar a ciência.

Essa ampliação se deu, por exemplo, a partir da incorporação da chamada hermenêutica fenomenológica elaborada por autores como M. Heidegger e H. G. Gadamer (ROUSE, 1990). Através dessa incorporação pôde-se perceber e reforçar a percepção a respeito da presença no "interior" da ciência de novas dimensões até então ignoradas ou negadas pela maioria dos filósofos. Contudo, a percepção da presença dessas outras dimensões não foi suficiente para que o recurso à hermenêutica desses resultados inequívocos. Isso aconteceu, em parte, porque ainda subsiste a dúvida de se a hermenêutica é aplicável às ciências naturais. Vale a pena lembrar que, para tornar ainda mais controversa a aplicação da hermenêutica às ciências naturais, os seus principais representantes na metade do século XX (Heidegger, Gadamer e Ricoeur) não se preocuparam em analisar cuidadosamente a possibilidade de a ciência se enquadrar em seus esquemas filosóficos.

Para certos comentadores, os três filósofos acima rejeitaram essa possibilidade. Essa posição foi defendida por autores como Karl Otto Apel e Charles Taylor. Uma possível explicação para esse comportamento é a seguinte. Entre esses autores ainda era forte a tese de que a hermenêutica, por lidar com interpretações, não teria como ser aplicada às ciências naturais, as quais estariam consagradas à explicação de como a natureza se organiza. A posição de autores como Apel e Taylor é coerente com o desenvolvimento da hermenêutica ao longo do século XIX, época em que ela foi entendida como capaz de conferir cientificidade às chamadas ciências humanas. No entanto, em nossos dias, a posição que aceita a aplicabilidade da hermenêutica vem sendo levada à sério. Seu principal trunfo é que ela corrobora várias conclusões obtidas "empiricamente" pelos estudiosos dos Science Studies. Essas conclusões mostram que a política e a cultura efetivamente participam da constituição da ciência e não apenas em períodos esporádicos e raros como aqueles que Kuhn denomina como crises. 
Os desenvolvimentos em três áreas diferentes (autônomas, mas com fortes relações de influência entre si), principalmente no último quartel do século XX, reforçaram a necessidade de se proceder a uma revisão de algumas das principais concepções propaladas pelo remanescentes do Positivismo Lógico e do Racionalismo Crítico. No lugar dessas concepções, foram sugeridas outras, as quais, por sua vez, geraram um sentimento de repulsa, uma vez que se pensou que elas seriam relativistas, anti-realistas e anti-racionalistas. Adesão e repulsa foram sentimentos que dividiram a comunidade da filosofia da ciência. A divisão acirrou-se ainda mais quando se percebeu que não seria fácil convencer os partidários das análises sociológicas e históricas dos seus erros eventuais. Alguns filósofos, norte-americanos em sua maioria e com trânsito pela filosofia continental, iniciaram um movimento em busca de uma filosofia capaz de, simultaneamente, rejeitar as consequências relativistas, antirrealistas e antirracionalistas, bem como respeitar as conclusões presentes nos estudos de caso, alcançadas pelos sociólogos e historiadores da ciências. Essas conclusões estabeleciam uma imagem da ciência com as seguintes características: local, não-universal, não-cumulativa, dependente de decisões e critérios extracientíficos e vinculada à tecnologia. Tendo em vista essas características, uma opção que apareceu válida foi a hermenêutica, já que esta parecia aceitar a naturalidade dessa imagem de ciência. Ao menos no interior do mundo filosófico anglo-saxão, Kuhn representa, para praticamente todos os defensores da aplicabilidade da hermenêutica às ciências naturais, o papel de pai fundador: a inevitabilidade da junção da hermenêutica à filosofia das ciências naturais dá-se com ele.

Houve no interior da filosofia continental outro movimento, simultâneo à absorção das ideias kuhnianas, cujo enfoque se deu na revisão do pensamento de Heidegger. Até a década de 1960, o autor de Ser e Tempo era visto como pouco interessado em questões ligadas à ciência. Para a maioria de seus comentadores, Heidegger, na verdade, não tinha razões para se sentir obrigado a pensar sobre a ciência, uma vez que as suas reflexões situavam-se no plano ontológico, enquanto as ciências localizar-se-iam no plano ôntico. A partir daquela época, alguns poucos estudiosos de Heidegger começaram a afirmar que ele não era - assim tão - desinteressado das coisas da ciência e muito menos anticientificista como parecia. A revisão do pensamento de Heidegger andou, no entanto, a passos lentos; mais rápidos foram os historiadores e sociólogos da ciência que incorporaram o pensamento de Kuhn, inclusive radicalizando contra o seu "guia" intelectual muitas de suas próprias ideias. Como é bem conhecido, Kuhn rejeitou todas as conclusões radicais de seus supostos "defensores". 
Independentemente das críticas de Apel, Habermas e Taylor, permaneceu no ar a ideia de que a hermenêutica poderia desempenhar um duplo papel (ou função). Martin Egger, por exemplo, recorre à explicação gaddameriana do papel da interpretação da obra de arte para refutar as críticas de Habermas e Giddens. Por um lado, a hermenêutica parece corresponder à imagem de ciência que resulta da história e da sociologia da ciência. Por outro, ela parece ser a melhor, ou mesmo a única, opção filosófica para aqueles que respeitam os resultados históricos e sociológicos dos Science Studies e desejam evitar os excessos cometidos pelo relativismo e pelo objetivismo radicais. Se a sugestão de se recorrer à hermenêutica mostrar-se adequada e fecunda, seria possível manter a crença no realismo (EGGER, 1993 a/b), uma vez que os resultados da ciência não são colocados em xeque.

Como se afirmou antes, não se pode pensar que os defensores de uma hermenêutica adequada às ciências naturais corroborem as mesmas ideias. Não apenas as teses defendidas são diferentes, mas também o escopo de atuação e a responsabilidade dessa perspectiva hermenêutica são variados. Por exemplo, Patrick Heelan, um dos mais antigos defensores da "empregabilidade" da hermenêutica como instrumento de análise da ciência, pensa que a hermenêutica possui um amplo escopo de atuação, atingindo domínios para fora da ciência. Segundo Heelan, a hermenêutica é mais bem "equipada" do que a filosofia tradicional para estudar os aspectos dinâmicos, narrativos, históricos e "quotidianos" da ciência. Parte da explicação do porquê a hermenêutica ser mais bem "equipada" é apresentada por ele mesmo: a filosofia tradicional da ciência estaria apenas preocupada com o cumprimento do objetivo cultural de dar suporte à pesquisa teórica interessada em controle e administração. Esse tipo de filosofia da ciência estaria distante da vida humana e da história, que são necessárias para temas mais amplos e perenes. Ainda que Heelan perceba na hermenêutica algo como um "instrumento" de crítica cultural, a principal contribuição da hermenêutica corresponde a resultados internos à esfera da filosofia da ciência, mesmo que os seus argumentos nos pareçam frágeis visto que genéricos.

Rouse (1991) é explícito em sua tese de que a hermenêutica será útil, caso ela efetivamente contribua para a superação das fronteiras da epistemologia. A rigor, Rouse parece esposar a ideia de que é da "natureza" da hermenêutica transgredir fronteiras e limites. Um terceiro autor importante nas discussões das relações entre hermenêutica e ciência natural é Don Ihde (s.d.), um dos mais radicais defensores da necessidade de se usar a hermenêutica para compreendermos as ciências naturais, e não apenas as ciências humanas. No entanto, ele afirma que a própria hermenêutica tem que se modificar para poder exercer o papel que lhe é atribuído. Para Ihde, a concepção que a hermenêutica "clássica" (este termo é 
nosso) tem da ciência é positivista, já que a entende como possuindo um modo genuinamente empírico para relacionar-se com o mundo natural. As ciências, continua ele, seriam realistas, enquanto que as ciências humanas seriam relativistas. Finalmente, as ciências naturais revelariam a realidade tal como ela é, o que seria vedado às ciências humanas, responsáveis pela produção de interpretações.

Se a hermenêutica é a análise filosófica das interpretações, afirma Ihde, obrigatoriamente tem que se preocupar com os modos segundo os quais a realidade pode ser "presentificada" para as pessoas. Em outros termos, a percepção tem uma dimensão hermenêutica, uma vez que ela constitui a relação entre os seres humanos e a realidade. Não se deve esquecer que a realidade apresenta-se aos seres humanos em aspectos específicos, particulares e nunca como totalidade. A ênfase dada à percepção permite a Ihde ligar a hermenêutica à ciência e à tecnologia, expandindo-a. É bem conhecido que as ciências naturais necessitam de percepções. Mas, estas últimas, em muitos casos, diferem bastante daquelas percepções que conseguimos diariamente através das nossas vidas cotidianas. Em outras palavras, são muitas as percepções científicas somente alcançadas através de instrumentos científicos. Ou seja, a tecnologia serve, talvez esta seja a sua principal razão de ser para a ciência, de mediadora entre a realidade e os cientistas. Os dados científicos, assim obtidos, precisam ser interpretados; não são, portanto, meros substitutos dos elementos que constituem a realidade.

A mediação produzida pela tecnologia possibilita a elaboração de duas interpretações possíveis: uma fraca e outra forte. A primeira (fraca) concede à tecnologia uma função de interface; a tecnologia fornece acesso aos fenômenos. A interpretação forte vai mais além, atribuindo um papel mediador que não é e nem pode ser neutro. A tecnologia não se limita a descrever ou retratar a realidade, mas ela co-determina o modo segundo o qual a realidade pode estar presente para os cientistas e ser interpretada por eles.

A interpretação forte, defendida por Ihde, tem claras implicações para a hermenêutica, que não se reduzem à expansão da hermenêutica às ciências naturais. Essa interpretação produz outro efeito sobre a hermenêutica que é de levá-la a se preocupar com a materialidade, sem abandonar a sua antiga preocupação com os textos. A expansão da hermenêutica do texto para a coisa torna possível vincular a filosofia da ciência com a filosofia da tecnologia. As ideias de Ihde foram elaboradas a partir das imagens de ciência produzidas pelos Science Studies desde meados da década de 1970. Em breves palavras, essas imagens apontam para uma concepção de ciência local, desunificada, historicamente produzida e influenciada por fatores epistêmicos e não epistêmicos, 
o que, num primeiro momento, aponta para a negação da distinção entre contexto da descoberta e contexto da justificação. Entre este último, podem ser apontados, por exemplo, a competição entre grupos ou equipes de cientistas. Os métodos usados o são a partir de problemas específicos, os quais podem modificar aqueles. Ao desenvolverem as suas concepções de ciência, os adeptos dos Science Studies estavam preocupados em superar os impasses causados pela manutenção da validade da distinção entre externalismo e internalismo. Em suma, os Science Studies rejeitam explicitamente toda e qualquer preocupação com a legitimação de certa concepção de ciência, ainda que seja possível verificar entre alguns deles como Peter Galison uma preocupação em manter válida a crença geral na ciência.

O abandono do projeto de legitimação da ciência, que foi uma das razões responsáveis pela criação da área da filosofia da ciência no início do século XIX, tornaria possível perceber a ciência como uma forma específica de cultura, o que poderia contribuir para a diminuição das tensões existentes entre os discursos sobre a natureza e a cultura. Esse objetivo, como se sabe, é explicitamente procurado pela hermenêutica. Uma possível contribuição da hermenêutica para a filosofia da ciência seria mostrar que a ciência é uma forma cultural específica, mas sem que isso possa implicar a adesão ao relativismo, aqui compreendido como uma postura que nega às teorias científicas todo e qualquer contato com o real.

Tendo em vista o que foi afirmado anteriormente, a melhor conclusão que pode ser extraída das tentativas feitas de aproximar ciência natural e hermenêutica aponta para a necessidade de mudanças nas duas. Sem estas mudanças, que já estão em curso, a se acreditar no que dizem os Science Studies, todo e qualquer diálogo continuará impossível.

\section{$-2-$}

O filósofo búlgaro Dimitri Ginev é autor de uma vasta obra dedicada à hermenêutica fenomenológica; em particular, seus livros e artigos são escritos em favor da existência de uma perspectiva hermenêutica da ciência natural. Ao lado de pesquisadores como Patrick Heelan, Joseph Kockelmans, Theodor Kisiel, Robert Crease, para ficarmos com os nomes mais conhecidos, Ginev considera que a perspectiva avançada por Martin Heidegger em Ser e Tempo adequa-se, desde que sofra ajustes, à prática científica presente em domínios científicos como a física e a biologia. Uma das vantagens percebidas na interpretação da ciência natural a partir da filosofia heideggeriana encontrar-se-ia 
na sua capacidade de superar os problemas persistentes e incontornáveis que acometem as análises produzidas em clave positivista e racionalista.

Na primeira parte do presente artigo, descrevi e expliquei a natureza e as consequências desses problemas. Uma das muitas vantagens da hermenêutica, segundo o próprio Ginev, estaria localizada na sua capacidade de manter como válida o conteúdo cognitivo normalmente atribuído à ciência. Em contraste com interpretações desconstrutivistas, também elas oriundas do universo da hermenêutica, Ginev pensa que a pretensão da ciência de se considerar como capaz de explicar verdadeiramente a natureza é correta e justa.

Ao se mostrar favorável às pretensões cognitivas da ciência, Ginev deliberadamente pretende afastar-se de interpretações pós-modernas ou relativistas da ciência, as quais teriam sido propostas principalmente por Kuhn, Rorty e Feyerabend uma vez constatados os impasses positivistas, empiristas, instrumentalistas e estruturalistas. O maior problema das interpretações pós-modernas ou relativistas estaria na negação de qualquer valor cognitivo da ciência, o que faria com que esta última deixasse de ser um conhecimento específico sobre a natureza, acarretando a perda da sua autonomia. Em outros termos, a ciência não mais poderia ser considerada como um conhecimento legítimo sobre a natureza. Em artigo publicado 2005, encontramos, nas palavras do próprio Ginev, a descrição de uma das suas metas:

...não obstante a radicalidade das transformações sugeridas pela tendência em voga na filosofia da ciência, a obrigação de se defender a autonomia cognitiva da ciência não deve ser abandonada. É claro que esta defesa não implica o repúdio ao esforço por uma nova identidade filosófica da ciência [constituída] para além do cientificismo, essencialismo e representacionismo. Novamente, a tarefa de elaboração de uma tal identidade deve ser obtida através de uma reflexão interna (hermenêutica) sobre as práticas científicas e não pela imposição dos propósitos externos do criticismo cultural e social (GINEV, 2005, p. 192; a tradução é minha.)

A citação acima me interessa não apenas por exemplificar com precisão um dos objetivos de Ginev, mas também por afirmar que a reflexão - isto é, a análise - hermenêutica deve se preocupar - ou seja, deve dirigir o seu foco - para as práticas científicas efetivas. Desse modo, o filósofo, ao procurar formular uma 
nova resposta para a pergunta "o que é a ciência?", deve se orientar conscientemente pelas ações e decisões, bem como pelos pressupostos de todo e qualquer tipo a elas subjacentes.

A decisão de dirigir o foco para as práticas científicas também pode ser encontrada num outro grupo de estudiosos - majoritariamente constituído por historiadores e sociólogos da ciência -, que, pelo menos desde meados da década de 1960, defende a tese de que a filosofia tradicional, por se interessar principalmente pelos aspectos teóricos do fazer científico, não consegue captar apropriadamente a natureza da ciência. Aqui não é o lugar para se comentar quando e como surgiu esse movimento, conhecido pela expressão de Science Studies, nem mesmo para entrar em detalhes a respeito das suas teses mais relevantes. Contudo, permito-me observar, contando com a indulgência dos meus leitores, que não é estritamente correto afirmar que os Science Studies, ao menos na sua totalidade, comunga de uma perspectiva anti-científica. É possível perceber em muitos dos seus mais famosos adeptos uma postura claramente favorável à autonomia cognitiva da ciência. Certamente, as estratégias de que fazem uso para garantir a existência de uma tal autonomia são em muito distintas daquelas privilegiadas por Ginev. $\mathrm{O}$ exemplo que mencionarei é o do historiador da ciência norte-americano Peter Galison, ele mesmo citado por Ginev em algumas de suas publicações.

A menção ao nome de Galison mostra que Ginev conhece algo do universo temático e conceitual dos Science Studies. Essa impressão confirma-se pelas referências feitas a outro autor desse universo: Hans-Jörg Rheinberger. Ginev não se limita a mencioná-los, ele vai mais além a ponto de se apoiar nas conclusões que Galison e Rheinberger obtêm em seus estudos de caso referentes à física e à biologia molecular com o intuito de provar fecundidade da perspectiva por ele elaborada.

Antes de comentar as referências que Ginev faz das ideias de Galison, parece-me útil apresentar algumas delas, o que é o objetivo do tópico abaixo.

\section{Galison e a ciência como cultura}

Não constitui exagero afirmar que, nos dias que correm, Galison é um dos mais importantes e conhecidos historiadores da ciência. Formado em física e história, ele, desde o final da década de 1970, vem se consagrando por fornecer narrativas históricas extremamente detalhadas da física de partículas elementares, talvez a área mais importante da física na segunda metade do século passado. Como exemplos comprobatórios dessa afirmação, permito-me a referência 
a algumas resenhas publicadas a respeito da sua obra Image and Logic - $A M a-$ terial Culture of Microphysics (GALISON, 1997). As resenhas publicadas são unânimes em afirmar a novidade das teses propostas por Galison. Ao enfatizar a necessidade de estudos locais em laboratórios físicos de modo a compreender a cultura dessa ciência, Galison defendeu a correção de algumas teses filosóficas propostas no início da década de 1980 por filósofos como Ian Hacking e Nancy Cartwrigth. No entanto, ele não se limita a mostrar a necessidade de se romper, no interior das análises sobre a ciência, com o domínio da teoria com relação à observação, uma das consequências da revolução provocada por Kuhn nos mundos da história e da filosofia da ciência a partir da publicação em 1962 de seu clássico A Estrutura das Revoluções Científicas. Galison introduziu todo um conjunto de conceitos de modo a tornar evidente sua própria concepção. Esses conceitos são oriundos principalmente dos domínios da linguística e antropologia. Segundo suas próprias palavras:

Aquilo que extraí dos linguistas antropólogos foi uma simples observação que eu esperava pudesse abrir um espaço histórico. A observação consistia em que as linguagens não podem, pura e simplesmente, ser consideradas como globais: elas estão permanentemente, de uma forma local, em fluxo, e essas alterações desenrolaram-se na História (GALISON, 1999, p. 398).

O uso que Galison faz de ideias oriundas dessas áreas das chamadas ciências humanas é determinado pela sua crença na tese de que:

[...] nos Science Studies havíamos adquirido uma importante perspectiva devido ao facto de nos concentrarmos em circunstâncias locais - as pessoas, as instituições e as técnicas particulares efectivamente envolvidas na produção e reprodução de experiências (GALISON, 1999, p. 398).

Com a citação acima, pretendo exibir a inserção bem particular e específica de Galison na tradição inaugurada por Kuhn no início da década de 1960. Em outras palavras, Galison, como Kuhn, crê que não é possível compreender a ciência sem que as reflexões epistemológicas surjam de análises históricas precisas e detalhadas. À diferença de Kuhn, e como já afirmado mais acima, Galison 
não vê a ciência como uma atividade principalmente voltada para a produção de teorias. Para ele, teoria e experiência são mundos distintos, ainda que interajam. A autonomia da experiência, ou do laboratório como prefere dizer Galison, é tão forte que até a periodização usual da física deve sofrer modificações:

Em vez de periodizar a história da Física por pontos de ruptura puramente ditados pela teoria (1900: descontinuidade quântica; 1905: relatividade especial; 1915: relatividade geral; 1925: mecânica quântica; 1947: electrodinâmica quântica), comecei a trabalhar em termos de uma imagem tripartida, na qual a instrumentação, a experiência e a teorização caminhavam cada uma delas ao seu próprio ritmo. Uma tal imagem parecia oferecer uma epistemologia histórica... [...] Mas por volta de 1989 tornou-se-me claro que, na exacta medida em que os níveis eram autonômos uns relativamente aos outros, eles não se podiam reforçar mutuamente (GALISON, 1999, p. 397).

As três citações anteriores de Galison são suficientes, assim eu o espero, para mostrar que suas ideias são merecedoras de consideração por parte de todo aquele que se dedica à história e à filosofia da ciência. Essa ideia recebe uma ênfase especial quando se recorda que sempre constituiu um desafio para os filósofos apresentar - justificadamente - os liames que existiriam entre o conhecimento - em especial, a ciência -, a cultura e o tempo histórico em que um determinado conhecimento científico aparece. Durante muito tempo, e devido à influência exercida por correntes filosóficas e sociológicas próxima ao marxismo, afirmou-se que a cultura e as relações sócio-econômicas influenciariam os conteúdos das teorias científicas e mesmo os resultados experimentais. Não constitui novidade alguma afirmar que essas teses foram enfaticamente criticadas e rejeitadas por serem vistas como artificiais. Sou da opinião que as ideias de Galison permitem retomar a perspectiva mais geral presente nessa corrente que defende uma estreita relação constituinte entre ciência e sociedade sem que se caia nos maniqueísmos frequentes nas análises externalistas da ciência, provocados pela aplicação ingênua e exagerada de princípios como o de causalidade.

Desde o início de Image and Logic, Galison se propõe a ir além da longa e enfadonha discussão sobre internalismo e externalismo na história da ciên- 
cia, introduzindo na discussão uma outra dicotomia (que ele obviamente não apresenta como nova): experimento versus teoria. Nesse caso, sua estratégia é apresentar os limites dos chamados positivistas lógicos, cuja ênfase ao fazerem história da ciência (em especial, da física) recaía no experimento. Para essa escola, o experimento pode ser visto como uma linha quase "temporal" (no sentido de intermitente), enquanto, sobre ela, as teorias vão se "quebrando", perdendo validade, sendo deixadas de lado ao serem confrontadas com os resultados experimentais, estes, sim, soberanos. A seguir, Galison critica - talvez, o termo criticar seja exagerado no seu caso; ele, sem dúvida, é extremamente diplomático no lidar com seus colegas e com ideias de outras vertentes de pensamento - a linha antipositivista, cujo principal representante é Kuhn. Ele aponta os limites dessa escola, que privilegia a teoria em detrimento da experimentação, como se o esquema dos positivistas lógicos fosse virado - na imagem de Galison - de pernas para o ar. Feito isso, ele introduz - em seus próprios termos - uma terceira subcultura, a instrumentação e com ela incorpora novos - e até então - desconhecidos personagens em seu escritos: engenheiros, técnicos de alto vácuo, torneiros, eletricistas, químicos industriais, etc. Certamente, para uma geração de físicos do século 20, muitos desses novos atores não mereceriam o título "cientista".

No entanto, Galison aponta - com certa razão - que apesar dos enfoques quase opostos de positivistas e antipositivistas, essas duas correntes de pensamento mantêm em comum um tipo de programa que busca unificar a ciência (que para Galison nasceu com a Escola de Viena e seus membros). Na verdade, Galison aponta que um dos "problemas" com a doutrina antipositivista é o fato de ela não romper com esse programa de unificação, apesar de passar a privilegiar a um enfoque a partir da teoria para a história da física no século passado.

Antes disso, porém, Galison já havia mostrado que o conceito de físico experimental há muito - ou seja, principalmente após a Segunda Guerra - perdeu o sentido original do termo. A imagem-padrão desse profissional da ciência - aquele que, como nos tempos de Rutherford, fabricava sua aparelhagem, a montava, fazia e anotava as medições, calculava resultados, escrevia o próprio artigo (sendo ele, muitas vezes, o único autor), como era comum nos tempos de Rutherford - deixou de existir. Ele mostra, de modo bem convincente, que parte dessas tarefas foi delegada a outros setores. O caso clássico é o dos físicos que passaram a trabalhar com emulsões depois da Segunda Guerra (VIEIRA, 2012). A missão agora pela feitura da "aparelhagem instrumental" recai sobre químicos industriais, que, segundo Galison, a fabricavam com gosto para seus colegas, exigindo em troca apenas o seguinte que os físicos jamais poderiam conhecer a composição dessas novas chapas fotográficas com aplicação à física nuclear. Essa exigência causou ansiedade entre os físicos. 
Ao mesmo tempo, Galison aponta como a autoria dos artigos mudou no pós-Segunda Guerra. Vale lembrar que artigos científicos assinados por quatro físicos na segunda metade da década de 1940 chegavam a causar espanto em alguns colegas. Com o advento das grandes máquinas e dos detectores, artigos, como o da descoberta do quark top, por exemplo, chegaram a ter quase mil autores.

Essa "industrialização" da física depois da Segunda Guerra fez com que o experimentador - ou pelo menos parte considerável de participantes de grandes grupos experimentais - nem mesmo chegasse a ter contato com o experimento em si, seja para coletar, seja para discutir resultados experimentais.

Como, então, fazer com que esses três tipos de subculturas "quase autônomas" (expressão de Galison) convivam em harmonia para levar à frente a empreitada que é fazer ciência e, mais importante, se comuniquem? Nesse ponto, Galison toma emprestada uma ideia de seus colegas linguistas e antropólogos. Imagina - e este pode ser dito o ponto alto de seu modelo - uma zona de troca, assim como a que se estabelece quando culturas diferentes, como a do colonizador e a do colonizado, se encontram, mas se vêem também com a necessidade de estabelecer uma cooperação acima das diferenças culturais (comércio, por exemplo). Surge, nessa zona de troca, um tipo de pídgin, um tipo de dialeto que surge de forma espontânea e não necessariamente chega a receber uma estrutura formal sob a forma de uma gramática. Entre físicos de emulsões e químicos industriais no pós-guerra na Inglaterra teria surgido, portanto, um uma zona de troca. Porém, o que nos parece estranho nesse caso específico é Galison não discutir o fato de serem duas comunidades com objetivos díspares, uma voltada para uma atividade 'não lucrativa' e outra que naquele momento visava ao lucro e não queria ser "contaminada" pelo ethos da ciência. Outro exemplo do estabelecimento dessa zona de troca foi o caso de um grande projeto de física, no qual atuavam, além dos físicos, matemáticos, engenheiros, pessoal ligado à computação, etc. Para Galison, o conceito em torno da aleatoriedade era completamente diferente do ponto de vista de cada uma desses profissionais, mas estes estabeleceram uma espécie de pidgin para levar adiante as tarefas:

Para nós, na história e na filosofia da ciência, o resultado é que nos podíamos colocar certo número de questões que antes se encontravam simplesmente bloqueadas pela imagem de linguagem global. Por outras palavras, no esquema global, se um termo tivesse diferentes associações e objectos, então esses usos diziam- 
-se incomensuráveis, e supunha-se que os faladores das duas linguagens "habitavam mundos diferentes" e que qualquer comunicação entre eles era, no final de contas, ilusória. O meu interesse, pelo contrário, incidia sobre o domínio vacilante e movediço da instabilidade no qual os termos mediavam entre duas ou mais linguagens "parentes". Com efeito, pareceu-me que as línguas estáveis e parentes se encontram elas próprias em fluxo, que não há uma distinção ontológica fundamental entre línguas "puras" e línguas "híbridas": o inglês foi igualmente uma língua de comércio. Como também o são esses bastiões de estabilidade que se chamam "mecânica" e "química" (GALISON, 1999, pp.398-399).

Assim, Galison se desloca da sua linha de visada para a instrumentação, tratando essa última como uma cultura material do século passado. Cultura material? A adoção dessa expressão tem certamente conotações marxistas. Porém, Galison já foi criticado por ser pouco marxista em sua análise. Não que esse epíteto não lhe coubesse bem. Na verdade, todos os elementos marxistas parecem estar presentes em Galison, que, no entanto (e por razões desconhecidas), parece não quer ir além de insinuações.

Ao inserir a instrumentação como uma amálgama entre o que são para ele as duas outras subculturas da física do século 20 - a saber, a experimentação e a teoria -, ele traz para a história da física de partículas do século passado personagens novos e até então desconhecidos, como químicos, técnicos, engenheiros, como se essa introdução fosse um tipo de "resgate" social com essas classes "esquecidas" (menos favorecidas, para usar uma terminologia mais ao molde "social").

Galison optou por escrever a história da física de partículas no século passado através da perspectiva da instrumentação. Para ele, física experimental não se faz sem máquinas ou sem as graxas que impregnam as mãos dos técnicos e dos experimentais, como afirma numa passagem na abertura de Image and Logic. A instrumentação, para Galison, é mais uma subcultura da física do século passado, em mesmo pé de igualdade (histórica, filosófica e epistemológica) que suas "irmãs mais velhas", a teoria e a experimentação. A instrumentação, por sinal, desfruta da sua "quase autonomia", como as outras duas subculturas do tripé. Ou seja, ela pode se manter dentro de seu "paradigma" (para usar um termo kuhniano), enquanto teoria e experimentação se enfraquecem ou mesmo são abandonadas, ou sofrer suas próprias "revoluções" (aproveitando-se 
de Kuhn novamente), quando as outras subculturas continuam paradigmáticas.

Para Galison, as máquinas (representações materiais dessa cultura material que é a instrumentação) não são neutras. Pelo contrário, chegam a ser clones (para usar uma nomenclatura em voga neste início de século) de seus idealizadores/construtores.

Essa visão alargada de Galison torna difícil achar em seus livros um fio condutor para classificá-lo (talvez, isso seja proposital). Isso faz dele quase um resenhista da ciência e cuja pessoa (ou princípios ideológicos) não importam - numa comparação grosseira, isso o torna um jornalista correspondente de guerra que faz de si mesmo uma não-pessoa, não-ator, e cuja opinião pessoal é dispensável para a reportagem dos eventos a que ele presencia. Galison, muito novo, conviveu com alguns dos maiores expoentes da física de partículas do século passado, o que foi muito importante para a redação de seus primeiros livros, publicados entre as décadas de 1980 e 1990. Em resumo: o foco parece ser sempre o objeto, a cultura material, e os meios, ou modos de produção, de fazê-los ou, pelo menos, os modos para entendê-los. Tudo sem uma ideologia como ponto de partida. A história, em Galison, às vezes, parece asséptica.

Mas, não é só isso. Galison se vale de uma retórica poderosa para convencer seus leitores. Juntamente com ela, vem um sem-número de citações, que vão das fábulas de Esopo à arquitetura moderna, passando pela antropologia, direito, artes, linguística, sem contar, obviamente, com os ingredientes mais previsíveis: a filosofia, a sociologia e a própria história. Chega-se a ter a impressão que fazer história, no sentido galisoniano, é um tipo de "anything goes", para aproveitar a máxima de Paul Feyerabend. Por exemplo, no meio de ponderações sobre a controvérsia em torno da identidade de alguma partícula qualquer, é válido citar a passagem diferenças artísticas entre Michelângelo e David. No final, obviamente, todos esses elementos parecem se somar e se reforçar para dar sustentação à visão e a teses do historiador de Harvard.

Galison recorre com assiduidade às figuras de linguagem. Sua predileta parece ser a metáfora. Num dos vários momentos literários de seu texto (quase poéticos, pois Galison é um artífice da língua inglesa), ele explica por que optou por analisar o final dos experimentos (por sinal, How Experiments End é um livro de 1987 no qual Galison apresentou muito do que seria a base filosófica, epistemológica e histórica do que viria a ser Image and Logic). Sua imagem é a seguinte (aproveitando-se de Levi Strauss): o pôr-do-sol é o momento em que se pode repensar o dia como um todo, no qual se pode refletir sobre os acontecimentos com uma visão do todo, praticamente acabada. Porém, nem mesmo a metáfora parece ser imprescindível no modelo de Galison (Image and Logic termina afirmando 
que até as metáforas têm um fim). Porém, essas figuras de linguagem, bem como citações externas e/ou extemporâneas, parecem não ser necessárias ao final para dar sustentação ao modelo galisoniano, no qual elas são retiradas, como se nem o alicerce, nem a sustentação da estrutura se ressentissem disso. Para usar uma imagem cara a Galison - a da arquitetura -, seria como se, ao final da construção de um edifício barroco, retirássemos todos os elementos "excedentes" transformando-o numa construção da escola Bauhaus - que, por sinal, através de elementos básicos, porém indispensáveis, queria atingir um tipo de universalidade.

À retórica elegante e convincente de Galison, some-se uma aguda capacidade de síntese, o sentido de sistematizar complexidades históricas em elementos (muitas vezes hierárquicos), como se montasse um quebra-cabeças. Uma delas (e talvez a principal) é a divisão em que toda tradição da física experimental do século passado pode ser enquadrada em duas categorias distintas: a dos "imagicistas" e a dos lógicos. Assim, apesar das várias sínteses - muitas delas extremamente sedutoras -, parece não haver em Galison um elemento simplificador, uma linha condutora na qual se possa agarrar para percorrer os quase 100 anos de história da física que ele se propõe a contar.

A ausência explícita de uma linha condutora na narrativa não me parece ser acidental. De certo modo, tal ausência é imposta por uma conclusão a que Galison chega a partir de suas análises: é impossível manter a crença na existência de uma unidade - principalmente interna - da ciência. Segundo ele mesmo, a ciência é desunificada. Toda e qualquer tentativa de superar essa condição está fadada ao fracasso, posto que seria construída a partir do respeito excessivo a princípios epistemológicos distantes da prática científica. Uma proposta de unificação das diferentes disciplinas científicas decorreria de uma postura globalizante. Contudo, essa impossibilidade não deve ser confundida com a aceitação de que a incomensurabilidade é um fenômeno incontornável e insuperável, como se nada pudesse ser feito para superá-lo. A posição de Galison não é de submissão ou derrota frente à incomensurabilidade. Ao contrário, ele, por meio das suas narrativas históricas detalhadas, justifica a conclusão de que a incomensurabilidade não significa insulamento ou impossibilidade de comunicação entre as diferentes subculturas da física.

A dinâmica (interna) da ciência seria suficiente para evitar o insulamento decorrente do reconhecimento de que a física é desunificada, sendo constituída por pelo menos três subculturas distintas, como visto anteriormente, desde que ela incorpore um elemento muito especial: a contingência. Nas palavras daquele que foi durante muito o tempo o enfant terrible da filosofia da ciência, 
o austríaco Paul Feyerabend, as análises extraídas desses microestudos sobre a ciência de laboratório nos levou para "bem longe da velha ideia (platônica) de ciência como um sistema de enunciados desenvolvendo-se por meio de experimentação e observação e mantido em ordem por padrões racionais duradouros" (FEYERABEND 2007, P. 14).

O espaço dedicado à exposição das teses de Galison não querem de modo algum transmitir a impressão de que considero que o seu projeto está essencialmente correto ou que ele é intrinsecamente superior ao de Ginev. Também tenho minhas diferenças com Galison (MENDONÇA; VIDEIRA, 2008). De modo muito breve, gostaria de mencionar apenas uma delas.

A partir da exposição, não é difícil ficar impressionado com a quantidade e qualidade dos detalhes da história da ciência escrita por Galison. Em que pese os seus méritos, no entanto, nós acreditamos que o seu calcanhar de Aquiles localiza-se numa de suas pressuposições metodológicas da sua concepção historiográfica, a saber: "an explanation on the same scale and of the same nature as the explanandum itself" (GALISON 1997, p. 36). Galison construiu seu imponente e funcional edifício sobre esta fundação. Ele se recusa a lidar com o contexto cultural e social no qual a ciência está baseada, alegando que isto seria uma questão de causas remotas e, portanto, irrelevante para a compreensão do tema. Por esta razão, apesar de ele produzir uma história, a qual, em muitos aspectos, não pode ser confundida com a tradicional inspiração Whig, ela ainda deve ser classificada de internalista, ou seja, circunscrita por fronteiras estabelecidas pela própria ciência. Não que tal trabalho seja desprovido de legitimidade, o problema reside na assunção de que há uma divisão como que natural entre duas entidades: ciência e sociedade. Como seriam mais ricas as histórias contadas por Galison caso ele levasse em consideração as relações - sem reificações a prior - entre a prática científica e a sociedade (civil) em geral. Isso não chega a ser um pedido muito complicado para um autor que se descreve como sendo, ele mesmo, um praticante dos Science Studies.

\section{"Para além de Galison?": Ginev e a afirmação exagerada de uma ontologia quasi-platônica}

É tempo de retomar a análise de Ginev sobre Galison, em particular no que diz respeito à conclusão específica deste último, a qual sustenta que a ciência é desunificada. Grosso modo, Ginev concorda com Galison. No entanto, e ain- 
da que não o diga explicitamente, sua atitude com relação a essa conclusão é que esta última de natureza empírica e não filosófica. Ela se impõe, mas não é conclusiva com relação ao projeto favorável à elaboração de uma postura justificacionista acerca da força cognitiva da ciência. A capacidade de explicar a natureza não pode ser obra do acaso. Em suas próprias palavras:

Yet in one respect I essentially disagree with Galison's views. What I cannot accept is his picture of a radical particularization of science. Indeed, there is a growing tendency of fragmentation of science which nowadays looks like a heterogeneous assemblage. The possibility of larger and more significant scientific (non-local and non-contingent) cultures rests, however, not only upon the coordination and convergence of research practices belonging to the different subcultures of science. In order to clarify this claim, one has to differentiate between the particularization of practices, language and methodological games, contexts of doing research, forms of a decontextualization of the research results, etc., and the level of the thematizing projects. In my view, Galison fails to work out such a differentiation. As a result, the disunity (and the dynamic unity) of science collapses (solely) to an assemblage of contingent subcultures. (By no means, this "contingent (dis)unity", nicely depicted by Galison, contradicts a "deeper disunity", which he ignores.) Paradoxically enough, it is the plurality of thematizing projects for constituting objects of inquiry that makes the "contingent (dis)unity" of the growing particularization of science into a "dynamic unity" of interrelated practices of scientific research (GINEV, 2007, p. 160-161; os negritos são meus).

De modo a evitar a presença incômoda da contingência, Ginev se socorre, como ele afirma, à possibilidade a projeção constituir os objetos de investigação. Estes devem se situar além dos horizontes de temporalidade, o que impede de serem eternos. Tais objetos são produzidos, tomam forma, no interior daquilo que Kuhn chama de ciência normal; nos termos de Ginev, eles são configuradas na cotidianidade das práticas rotineiras da pesquisa científica. Não existem 
práticas isoladas no interior do "mundo" da pesquisa científica. Cada prática específica só possui sentido no contexto de outras práticas, também presentes e efetivas. A interconexão desse conjunto de práticas detém uma prioridade ontológica com relação às práticas específicas. Consequentemente, "a constituição dos objetos de investigação é sempre temporal no interior da cotidianidade da ciência normal" (op. cit. p. 161). Por existirem apenas dentro das interconexões, os projetos de tematização fazem com que os objetos da investigação científica sejam classificados por Ginev como quasi-platônicos. Talvez porque considere que exemplificar seja algo que não cabe à filosofia, Ginev não nos dá nenhum exemplo desses objetos quasi-platônicos. Mas, são eles suficientes para evitar a presença da contingência? Não o creio.

A proposta de Ginev é, quanto a mim, insatisfatória. Em primeiro lugar, Ginev parece entender que contingência é uma característica apenas ontológica da ciência, esquecendo-se, ou não querendo ver, que ela pode ser política, uma vez que, como descreve Galison, resultados científicos (renormalização da eletrodinâmica quântica) tornaram-se possíveis graças a técnicas experimentais (por exemplo: radiação de microonda) aperfeiçoadas durante o projeto de construção da bomba atômica em Los Alamos, local em que Richard Feynman as aprendeu. A dimensão política aqui se coloca do seguinte modo: a construção da bomba atômica foi uma decisão tomada no domínio da política ou ainda: Los Alamos só existiu por causa da Segunda Guerra Mundial.

A segunda razão da minha insatisfação decorre da atitude de Ginev de recorrer a uma entidade - ou seria estrutura? - ontológica sem dar exemplos da mesma. Sua atitude lembra-me a de um mágico que tira um coelho da cartola. A ausência de exemplos históricos - os casos empíricos - na argumentação de Ginev fazem com que a sua crítica a Galison seja inútil, uma vez que ele não nos explica porque um justificativa filosófica vale mais do que uma narrativa histórica em se tratando de ciência.

Para evitar a contingência, tais "entidades" neo-platônicas, bem como os projetos de tematização, deveriam mostrar a presença de uma unidade, mesmo que dinâmica, na ciência. Neste caso, uma unidade de tipo ontológico, já que constitutiva da prática científica. Ou ainda: a unidade da ciência, para realizar aquilo que deseja Ginev, devesse ser anterior à prática, uma vez que passa a concretizar a sua meta ou o seu objetivo. Ao propor a necessidade de uma unidade de tipo ontológico Ginev dá a entender que não compreendeu bem os propósitos da filosofia da ciência de Kuhn a Galison passando por Feyerabend e Laudan. Para todos esses filósofos da ciência, certamente de formas diferentes 
entre si, a saída pela ontologia deveria ser evitada a todo o custo porque a dinâmica da ciência é interna a ela, o que seria perdido com o recurso à ontologia, uma vez que esta lhe é externa, ainda mais se avaliada a partir do ponto de vista válido no projeto hermenêutico.

Ao mesmo tempo em que vincula os seus objetos quasi-platônicos à interconexão das práticas, Ginev afirma, baseando-se em algo que lhe parece ter ares de um fato empírico, que a tendência perceptível de intensificação das práticas entre os domínios da pesquisa conduz ao aparecimento de uma globalização - o termo é dele mesmo, o que me leva a perguntar em que este termo difere do conceito de desmundanização caro à fenomenologia existencial - desta vinculação, sendo que até mesmo as zonas de troca, ou de comércio, de Galison seriam explicadas pela atuação dessa globalização. Esta última seria um indício da presença de uma unidade que se faz, i.e. que passa a existir, em cada momento em que os objetos de investigação são extraídos dos locais ems que são produzidos. É justamente aqui que reside o calcanhar de Aquiles da solução de Ginev. Explico-me.

Os objetos estudados pela física já há muito tempo se caracterizam pela sua capacidade intrínseca de se transformarem em outros objetos. Eles não são imutáveis e nem mesmo algo próximo disso. Como afirma Werner Heisenberg, as partículas elementares

\begin{abstract}
não são eternas nem invariáveis e, portanto, dificilmente podem ser chamadas "reais" na verdadeira acepção da palavra. São simples representações daquelas estruturas matemáticas fundamentais a que se chega por tentativas de continuar subdividindo a matéria; representam o conteúdo das leis fundamentais da natureza. Para a ciência natural, não há mais, no início, o objeto material, porém, forma, simetria matemática (HEISENBERG, 1969, pp. 26-27; a tradução é minha).
\end{abstract}

A força da simetria está na sua capacidade de instaurar uma dinâmica válida apenas no domínio em que as partículas elementares se localizam e existem. Essa dinâmica poderá ser diferente em outras regiões da natureza, uma vez que, após a formulação da lei de Planck, esta lei "prova pela primeira vez que há escalas na natureza e que fenômenos em diferentes graus de grandeza não são necessariamente do mesmo tipo" (HEISENBERG, 1969, p. 14). Cada região da natureza se diferenciaria de outras pela "obediência", ou não, a uma 
das constantes universais da física como a constante de Planck e a velocidade da luz. Nos termos de Galison, essa tese pode ser expressa do seguinte modo: "Mas, entre estas subculturas da física jazem territórios limítrofes substanciais, e é apenas através da exploração da dinâmica dessas regiões limítrofes que nós podemos ver como o todo se encaixa" (GALISON, 1997, p. xx)

Negar a existência de uma unidade da ciência não implica o não reconhecimento de sua natureza dinâmica. Ao contrário. Nem mesmo significa que a física passa a ser algo incoerente ou sem sentido. Como afirma Galison:

A física, como um todo, encontra-se sempre em um estado de coordenação incompleta entre as peças extraordinariamente diversas da sua cultura: trabalho, máquinas, evidência e argumento. Que estas peças desordenadas venham juntas tanto como aquilo que elas fazem revela a presença, não de um restrito cálculo de racionalidade, mas um senso de razão expandido" (GALISON 1997, p. xxii).

Talvez, e aqui a prudência se impõe, caiba à história da ciência, e não à filosofia, determinar retrospectivamente, uma vez os fatos já acontecidos, a coerência da prática científica. Se for a história da ciência a responsável por exibir a coerência desunificada da ciência, não se poderá dispensar um olhar atento sobre a figura do seu autor, o que nos leva a perguntar: para quem é produzida tal coerência? Para aquele que "fez" a história ou para aquele que a "narrou"?

\section{Conclusão}

Neste trabalho, procurei defender a possibilidade de se recorrer à hermenêutica como meio para a compreensão da natureza das ciências naturais. A despeito de algumas tentativas feitas desde a década de 1970, os resultados até hoje alcançados permanecem numa situação de incompletude, fazendo que com que sejam mais bem qualificadas como sugestões programáticas. Uma segunda conclusão, merecedora de destaque diz respeito à proposta elaborada por Ginev, a qual fracassa por duas razões; a primeira delas é o seu excessivo respeito à filosofia transcendental e o segundo a ausência da incorporação da necessidade de se discutir a natureza dos objetos físicos. 


\section{$\{$ Referência Bibliográfica}

BOMBASSARO, L. C. As Fronteiras da EpistemologiaComo se produz o conhecimento. Petrópolis: Vozes, 1992.

EGER, M. Hermeneutics as an Approcah to Science : Part I, Science \& Education, Vol. 1 337-348 e Vol. 2, pp. 1-29, 1993.

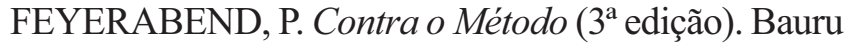
: Editora UNESP, 2007.

GALISON, P. Image \& Logic - A material culture of microphysics. Chicago/London: The University of Chicago Press, 1997.

GALISON, P. Culturas Etéreas e Culturas Materiais IN F. GIL (org.) A ciência tal qual se faz. Lisboa : Edições João Sá da Costa, pp. 395-414, 1999.

GALISON, P. e D. STUMP (orgs.). The disunity of science (Boundaries, Contexts, and Power), Stanford : Stanford University Press, 1996.

GINEV, D. Against the Politics of Postmodern Philosophy of Science. International Studies in the Philosophy of Science, Vol. 19, N², pp.191-208, 2005.

GINEV, D. A (Post)Foundational Approach to the Philosophy of Science: Part II. Journal for General Philosophy of Science, Vol. 38. N¹, pp.57-74, 2007.

HEELAN, P. A. The Scope of Hermeneutics in Natural Science, Studies in the History and Philosophy of Science, Vol. 29, Nº 2, pp. 273-298, 1998.

HEELAN, P. A. e J. SCHULKIN. Hermeneutical Philosophy and Pragmatism: A Philosophy of Science, Synthese, Vol. 115, pp. 269-302, 1998.

HEISENBERG, W.. Philosophische Probleme der Elementarteilchen Physik. Durchblicke. Martin Heidegger zum 80. Geburtstag. Frankfurt am Main: Vittorio Klostermann, 1970.
IHDE, D. Expanding Hermenutics, http://www.sunysb. edu/philosophy/faculty/papers/Expherm.htm. Acesso em 03/06/2005.

MENDONÇA, A. L. de O., A. A. P. Videira. "From representation to presentation - The old asymmetry in Galison”. Representaciones (Córdoba), v. 4, p. 49-66, 2008.

MURPHY, N. Scientific Realism and Postmodern Philosophy, British Journal for the Philosophy of Science, Vol. 41, pp. 291-303, 1990.

ROUSE, J. Knowledge and Power - Toward a Political Philosophy of Science, Cornell University Press, Ithaca, 1990.

ROUSE, J. Interpretation in Science. IN The Interpretative Turn (Philosophy, Science, Culture), Hiley, David R., James F. Bohman e Richard Schusterman, Cornell University Press, Ithaca e Londres, pp. 42-56, 1991.

ROUSE, J. Philosophy of Science and the Persistent Narratives of Modernity, Studies in the History and Philosophy of Science, Vol. 22, No 1, pp. 249-267, 1991 b.

VIDEIRA, A. A. P. A Filosofia da Ciência sob o Signo do Science Studies, Abstracta, Vol. 2, No 1, pp. 70-83 (http:// www.abstracta.pro.br/revista/volume2number1/4 videira.pdf). 2005.

VIEIRA, C. L. Um mundo inteiramente novo se revelou - Uma história da técnica das emulsões nucleares. São Paulo: Livraria Editora da Física, 2012.

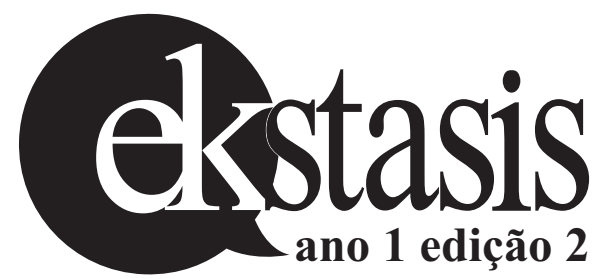

